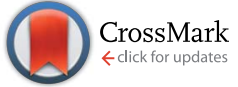

Cite this: RSC Adv., 2017, 7, 6114

Received 27th November 2016

Accepted 9th January 2017

DOI: $10.1039 / c 6 r a 27400 e$

www.rsc.org/advances

\section{Formation of cationic hydrophobic micro-blocks in P(AM-DMC) by template assembly: characterization and application in sludge dewatering $\dagger$}

\author{
Bingzhi Liu, ${ }^{\text {ab }}$ Huaili Zheng, ${ }^{\text {*ab }}$ Xiangrui Deng, ${ }^{\text {ab }}$ Bincheng $X u,{ }^{\text {ab }}$ Yongjun Sun, ${ }^{c}$ \\ Yongzhi Liu ${ }^{\mathrm{ab}}$ and Jianjun Liang ${ }^{\mathrm{ab}}$
}

\begin{abstract}
A template assembly method was introduced to obtain a cationic hydrophobic micro-block structure based amphiphilic electrolyte poly(acrylamide-co-2-methacryloxyethyltrimethyl ammonium chloride) P(AMDMC) in this work, thereby increasing charge density and enhancing charge neutralization ability at the same charge density. The alteration of copolymerization or homo-polymerization was evaluated by the changes in reactivity ratios, so as to unravel the mechanism of template assembly. The micro-blocks generated by the new distribution of sequences were demonstrated by ${ }^{1} \mathrm{H}$ nuclear magnetic resonance spectroscopy $\left({ }^{1} \mathrm{H}\right.$ NMR) and differential thermal-thermogravimetric analysis (DSC-TGA). Two negative controls were employed in sludge dewatering experiments to further evaluate the advanced properties of the template-assembled polymer. The results further verified that the positive effect of template assembly on flocculation performance of the polymer was achieved mainly through two ways: improving charge density and generating the micro-block structure. It can be concluded that the introduction of template assembly into polymerization can improve the performance of the polymer.
\end{abstract}

\section{Introduction}

In recent years, sludge treatment has become a focus due to its large yield and enormous pressure on the ecosystem..$^{1-4}$ Sludge is a complex, negatively charged colloidal system and contains over $99 \%$ water. The problem of dehydration difficulties has become the bottleneck of sludge treatment. ${ }^{5-8}$ Hence, it is essential to pretreat the sludge with chemicals prior to mechanical dewatering.

It is well known that flocculation is the most commonly used and effective method to agglomerate sludge tiny flocs and improve sludge filterability. ${ }^{\mathbf{3}, \mathbf{9}, 10}$ Polyelectrolyte is a water-soluble long-chain polymer with ionizable groups, in which polyacrylamide (PAM) and the derivatives appear to be ideal treatment agent in sewage and sludge flocculation process, especially the cationic PAM (CPAM). ${ }^{\mathbf{1 1}, 12}$ At present, CPAM research mainly focus on increasing cationic blocks under the condition of high intrinsic viscosity $[\eta]$, which can be achieved through selecting a structurally superior cationic monomer and controlling the reactivity ratio. Generally, charge neutralization and bridging were

${ }^{a}$ Key Laboratory of the Three Gorges Reservoir Region's Eco-Environment, State Ministry of Education, Chongqing University, Chongqing 400045, China. E-mail: 15922887515@163.com

${ }^{b}$ National Centre for International Research of Low-Carbon and Green Buildings, Chongqing University, Chongqing 400045, China

${ }^{c}$ Nanjing Technology University, College of Urban Construct, Nanjing 211800, Jiangsu, China

$\dagger$ Electronic supplementary information (ESI) available. See DOI: $10.1039 / \mathrm{c} 6 \mathrm{ra} 27400 \mathrm{e}$ considered to be the dominate flocculation mechanism. ${ }^{\mathbf{1 3 - 1 5}}$ For the flocculation of negatively charged particles, the role of charge neutralization becames particularly important. ${ }^{16,17}$ The magnitude of the neutralization effect primarily depends on the charge density (CD). Notably, the sequence distribution of the polymer was also closely related to the charge neutralization capacity. ${ }^{\mathbf{1 8}}$ Studies have shown that the introduction of the template exerted a certain effect on the radical polymerization, which was mainly reflected in the kinetics of the polymer (i.e., the reactivity ratio), the intrinsic viscosity $[\eta]$, the tacticity or the sequence distribution. ${ }^{18-21}$ Template-assembled polymerization was defined as such an assembly process that the monomers interacted with a pre-set macromolecule (template) by electrostatic forces, hydrogen bonding and covalent bonds, which can be treated as a simple analogy model for this type of reaction such as DNA or RNA or certain enzymatic reactions, as showed in Fig. 1. ${ }^{20,22}$

To the best of our knowledge, acryloxyethyltrimethyl ammonium chloride (DAC) and (2-methacryloyloxyethyl) trimethyl ammonium chloride (DMC) are the most commonly used quaternary ammonium salt monomers. ${ }^{23}$ Comparing the structural formula, it is clear that DMC has an extra hydrophobic group (methyl) than DAC, and some researches confirmed that the extra methyl group could improve the flocculation properties of DMC. ${ }^{24-26}$ Therefore, DMC is considered as a more amphiphilic cationic monomer containing both hydrophobic groups (methyl and backbone) and hydrophilic groups (quaternary amines groups with permanently positive charges).${ }^{27}$ Up to now, majority of researches has been on the preparation of flocculants with 

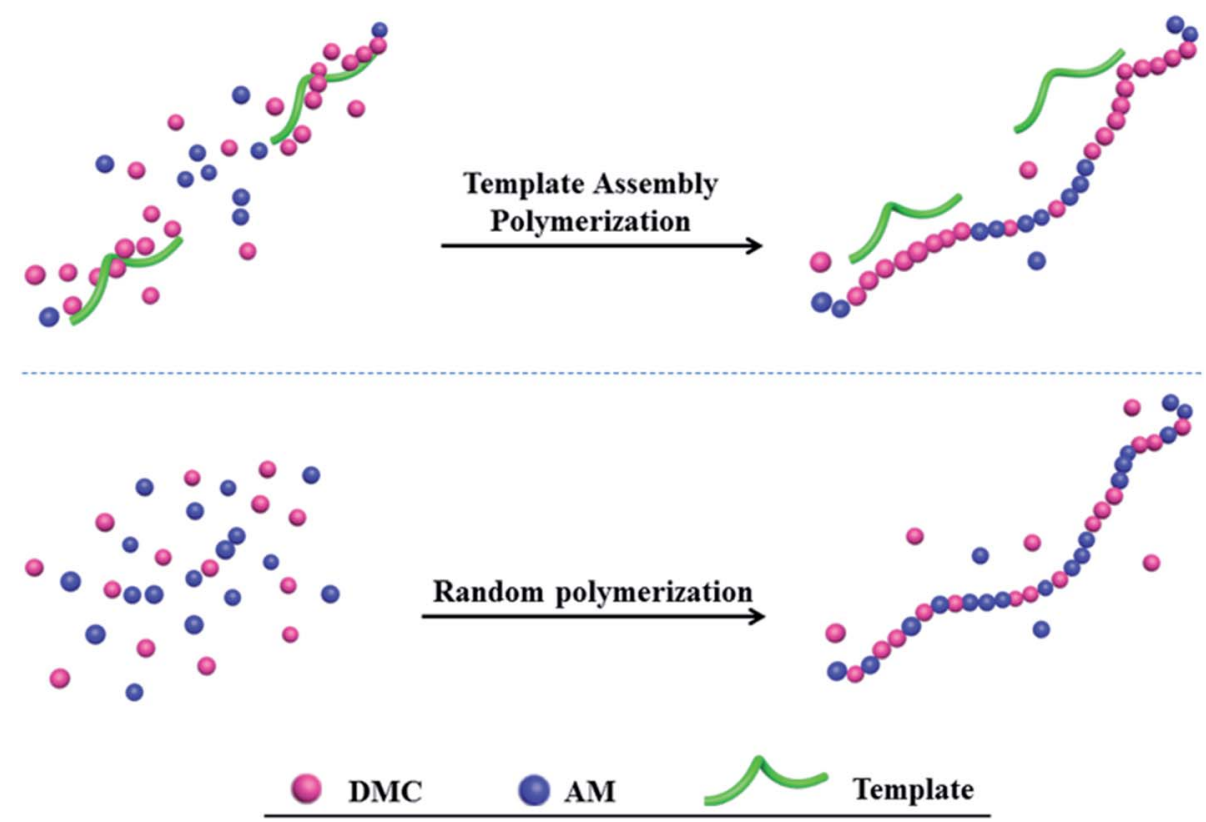

Fig. 1 Schematic of random copolymerization and template copolymerization.

DMC, but few studies focused on the optimization of cationic monomers distribution under high intrinsic viscosity $[\eta] .^{15}$

Thus, the primary objectives of this study were to: (1) prepare micro-blocks based amphiphilic electrolyte poly(acrylamide-co-2methacryloxyethyltrimethyl ammonium chloride) P(AM-DMC) with high intrinsic viscosity $[\eta]$ and high charge density $\mathrm{CD}$ by template assembly, using $\mathrm{AM}$ and DMC as monomers, and sodium polyacrylate as template; (2) unravel the mechanism of template assembly by determining the reactivity ratio of monomers before and after the addition of template; (3) confirm the cationic micro-blocks structure of template-assembled polymers by ${ }^{1} \mathrm{H}$ nuclear magnetic resonance spectroscopy $\left({ }^{1} \mathrm{H}\right.$ NMR) and differential thermal-thermogravimetric analysis (DSC-TGA); (4) evaluate the effect of micro-blocks structure and $\mathrm{CD}$ in the polymer on sludge dewatering performance by exploring their dosage-dependence, pH-dependence, sludge flocs morphology and sedimentation behaviors, and so forth.

\section{Materials and methods}

\subsection{Reagents}

Acrylamide (AM) and 2-methacryloxyethyltrimethyl ammonium chloride (DMC, $75 \mathrm{wt} \%$ in $\mathrm{H}_{2} \mathrm{O}$ ) were purchased from Lanjie Tap Water Co., Ltd. (Chongqing, China). Sodium poly-acrylate (NaPAA, MW3000, Shandong Xintai Water Treatment Ltd.) was used as template. The photo-initiator 2,2'-azobis[2-(2imidazolin-2-yl) propane] dihydrochloride (VA-044) was provided by Ruihong Biological Technology Co., Ltd. (Shanghai, China). Silver nitrate concentrate and Potassium dichromate were purchased from the Aladdin Reagent Network. $\mathrm{HCl}$ and $\mathrm{NaOH}$ were used to adjust the $\mathrm{pH}$. All aqueous and standard solutions were prepared with deionized water. The purity of nitrogen gas was higher than $99.99 \%$.

\subsection{Preparation of copolymer}

The synthesis reaction of the polymer was initiated by UV light (main radiation wavelength $300-400 \mathrm{~nm}$; average irradiation intensity, $2000 \mu \mathrm{W} \mathrm{cm}{ }^{-2}$ ). Setting the total monomer mass concentration as $30 \%$, a certain amount of monomers (AM and DMC), template NaPAA and photo-initiator VA-044 were dissolved in quartz reaction vessel by deionized water. The reaction vessel was purged with nitrogen for $30 \mathrm{~min}$ to remove oxygen completely. Afterwards, it was exposed to a high pressure mercury lamp for $60 \mathrm{~min}$ to initiate the reaction, then aged for 2 hours to complete the subsequent radical reaction. The gel-like product was dissolved in deionized water $(1: 10 ; \mathrm{V} / \mathrm{V})$ with the $\mathrm{pH}$ of the colloidal system adjusted, and then was washed 3 times with acetone and ethanol respectively, to obtain white extract. Finally, the product poly(acrylamide-co-2-methacryloxyethyltrimethyl ammonium chloride) $\mathrm{P}(\mathrm{AM}-\mathrm{DMC})$ was granulated, and dried in a vacuum oven at $40{ }^{\circ} \mathrm{C}$ for further use.

\subsection{Determination of reactivity ratio}

The reactivity ratio, one of the most important parameters related to the relative monomer activity, is calculated on the basis of the ratio of the homo-polymerization rate constant and the copolymerization rate constant of the monomer in the binary copolymerization. ${ }^{28}$ The molar ratio of AM to DMC in the copolymer (i.e., charge density $\mathrm{CD}$ ) was determined by silver nitrate titration ${ }^{29}$ and the details were placed in the ESI. $\uparrow$ The reactivity ratio of copolymer was determined by Kelen-Tüdös method, and the equation was represented in eqn (1)..$^{25,30}$

$$
\eta=\left(r_{\mathrm{AM}}+\frac{r_{\mathrm{DMC}}}{\delta}\right) \varepsilon-\frac{r_{\mathrm{DMC}}}{\delta}
$$


Table 1 Characteristics of sludge

\begin{tabular}{lllll}
\hline Indicator & $\mathrm{pH}$ & $\mathrm{SRF}\left(\times 10^{12} \mathrm{~m} \mathrm{~kg}\right)$ & $\zeta$-Potential $(\mathrm{mV})$ & Moisture content (wt\%) \\
\hline Value & $6.81 \pm 0.1$ & 16.1 & $-24.9 \pm 0.2$ & $98.8 \%$
\end{tabular}

where $\quad \eta=\frac{G}{H+\delta}, \varepsilon=\frac{H}{H+\delta}$ and $\delta=\left(H_{\max } \times H_{\min }\right)^{1 / 2}$; $G=\frac{R(p-1)}{p}$ and $H=\frac{R^{2}}{p} ; R=\frac{1-f}{f}$ and $\rho=\frac{1-F}{F}, R$ is the feed molar ratio of AM and DMC, and $\rho$ is the molar ratios of AM and DMC in the polymer at low conversion; $f$ is the molar mass fraction of DMC in the feed, and $F$ is the molar mass fraction of DMC in the polymer. After the $\eta$ and $\xi$ of each point were obtained, the linear fitting curve relating to $\eta$ and $\xi$ can be plotted, and the $r_{\mathrm{AM}}$ and $r_{\mathrm{DMC}}$ can be obtained through the slope and intercept of straight line.

\subsection{Characterization methods}

The dried sample was ground to fine powder for subsequent characterization. The intrinsic viscosity $[\eta]$ of polymerization was determined by Ubbelohde viscosity meter (Shanghai, China). FTIR samples were prepared as $\mathrm{KBr}$ pellets for infrared spectroscopy measuring in the range of $4000-400 \mathrm{~cm}^{-1}$, which was analyzed using a infrared spectrometer (550 Series II, MettlerToledo, Greifensee, Switzerland). ${ }^{1} \mathrm{H}$ NMR spectra were recorded on spectrometer (AVANCE-500, Bruker Company, Karlsruhe, Germany) with deuterium oxide $\left(\mathrm{D}_{2} \mathrm{O}\right)$ as solvent. DSC-DTA was conducted by a synchronal thermal analyzer (DTG-60H, Shimadzu, Kyoto, Japan) to examine the thermal stability of copolymers from Ambient temperature to $600{ }^{\circ} \mathrm{C}$.

\subsection{Dewatering experiments}

Raw sludge was obtained from Jiguanshi Sewage Treatment Plant in Chongqing. The characteristics of the sludge were listed in Table 1. Buchner-funnel filtration was used in the sludge dewatering. The main index used to indicate sludge conditioning efficiency were specific resistance to filtration (SRF), $\zeta$ potential, floc size and settling rate. In dewatering experiment, an aliquot of $100 \mathrm{~mL}$ raw sludge was placed into $500 \mathrm{~mL}$ beaker followed with flocculants added. Afterwards, the mixing procedure was conducted by a program-controlled jar test apparatus (ZR4-6, Zhongrun, China): rapidly stirred $30 \mathrm{~s}$ at a speed of $200 \mathrm{rpm}$ and then stirred $60 \mathrm{~s}$ at a speed of $50 \mathrm{rpm}$. The $\mathrm{pH}$ was adjusted with 1.0 M NaOH solution and $1.0 \mathrm{M} \mathrm{HCl}$ solution. The $\zeta$-potential and floc size distribution were measured by ZS90 Malvern potential analyzer (Malvern Instruments Ltd., UK) and a laser diffraction instrument (Mastersizer2000, Malvern, U.K.), respectively. The SRF was determined by the following equation..$^{1,2,31}$

$$
\mathrm{SRF}=\frac{2 b P A^{2}}{\mu c}
$$

where $P$ is the filtration pressure $\left(\mathrm{N} \mathrm{m}^{-2}\right), A$ is the filtration area $\left(\mathrm{m}^{2}\right)$, and $\mu$ is dynamic viscosity coefficient $\left(\mathrm{N} \mathrm{s} \mathrm{m}^{-2}\right), b$ is the slope calculated from the plot of $t / V_{\mathrm{f}}(y)-V_{\mathrm{f}}(x)$, where $V_{\mathrm{f}}$ is the volume of filtrate $\left(\mathrm{m}^{3}\right)$ and $t$ is the filtration time (s). $c$ is the weight of solids per unit filtrate volume $\left(\mathrm{kg} \mathrm{m}^{-3}\right)$, $c=\frac{\frac{1}{c_{\mathrm{i}}}}{100-c_{\mathrm{i}}}-\frac{c_{\mathrm{f}}}{100-c_{\mathrm{f}}} c$, where $c_{\mathrm{i}}$ is the initial moisture content (\%) and $c_{\mathrm{f}}$ is the final moisture content (\%).

\section{Results and discussion}

\subsection{Property comparison of TPA-D and PA-D at different} $f_{\mathrm{DMC}}$

The parameters used to study the properties of the polymers were the molar ratio of template and DMC monomers (T/D), and the molar mass fraction of DMC monomer in the total monomer content $\left(f_{\mathrm{DMC}}\right)$. As shown in Table $2, \mathrm{CD}$ values of the templateassembled polymers series (TPA-D) were clearly higher than the random polymer series (PA-D) under identical synthetic conditions with other parameters. This is because the template may channel the trajectory of the cationic monomers in the free radical polymerization process, thereby improving the polymerization efficiency to a certain extent. ${ }^{\mathbf{1 8 , 1 9}}$ In general, the activity of DMC monomer is lower than that of AM, so the higher the DMC monomer content, the lower the overall activity of the polymerization reaction system is. This could explain why intrinsic viscosity $[\eta]$ was decreasing with the increase of $f_{\mathrm{DMC}}$. In addition, judging from the results of $\mathrm{CD}$ under different $f_{\text {DMC }}$, it was worth noting that the assembly effect of template on DMC monomers was first enhanced and then weakened, which was the strongest in the range of $20-30 \%$. Since the templates were oligomeric macromolecules, excessive presence in the reaction system may form some spatial resistance, and accelerate the chain transfer and chain termination effects. ${ }^{22}$

\subsection{Effect of template on the reactivity ratio}

The relevant data for the reactivity ratio by the Kelen-Tüdös method were placed in Tables $\mathrm{S} 1$ and $\mathrm{S} 2, \dagger$ respectively, and the

Table 2 Comparison of intrinsic viscosity $[\eta]$ and CD of TPA-D and PA-D at different $f_{\mathrm{DMC}}$

\begin{tabular}{llllr}
\hline & & & Intrinsic \\
$f_{\text {DMC }}(\%)$ & Abbreviation & T/D & viscosity $\left(\mathrm{dL} \mathrm{g}^{-1}\right)$ & CD (\%) \\
\hline 10 & PA-D $_{1}$ & 0 & 11.02 & 4.35 \\
10 & TPA-D $_{1}$ & 1.0 & 10.90 & 7.95 \\
20 & PA-D $_{2}$ & 0 & 10.35 & 10.28 \\
20 & TPA-D $_{2}$ & 1.0 & 10.31 & 18.07 \\
30 & PA-D $_{3}$ & 0 & 10.83 & 17.65 \\
30 & TPA-D $_{3}$ & 1.0 & 10.23 & 27.39 \\
40 & PA-D $_{4}$ & 0 & 9.51 & 23.89 \\
40 & TPA-D $_{4}$ & 1.0 & 8.41 & 37.81 \\
50 & PA-D $_{5}$ & 0 & 8.34 & 31.67 \\
50 & TPA-D $_{5}$ & 1.0 & 7.41 & 43.97
\end{tabular}


linear fit data are plotted in Fig. 2. It is noteworthy that the accurate determination of the copolymer composition (i.e., the determination of $\mathrm{CD}$ ) is critical to the estimation of the monomer reactivity ratio, and CD values were also expressed as the $F_{\mathrm{DMC}}$ values in Tables $\mathrm{S} 1$ and $\mathrm{S} 2 . \dagger$ Furthermore, the reactivity ratios for $\mathrm{AM}$ and DMC monomers (i.e., $r_{\mathrm{AM}}$ and $r_{\mathrm{DMC}}$ ) showed a significant change, as listed in Table 3. Generally, AM monomers tend to homo-polymerization (i.e., $r_{\mathrm{AM}}>1$ ) in the polymerization reaction, while DMC monomers tend to copolymerize (i.e., $\left.r_{\mathrm{DMC}}<1\right) .{ }^{14}$ After the addition of the template, the value of $r_{\mathrm{AM}}$ was reduced, while the $r_{\mathrm{DMC}}$ increased more close to 1 , which means that both the copolymerization of AM monomers and the homo-polymerization of DMC monomers were enhanced. Thus, the changes in $r_{\mathrm{AM}}$ and $r_{\mathrm{DMC}}$ caused a new
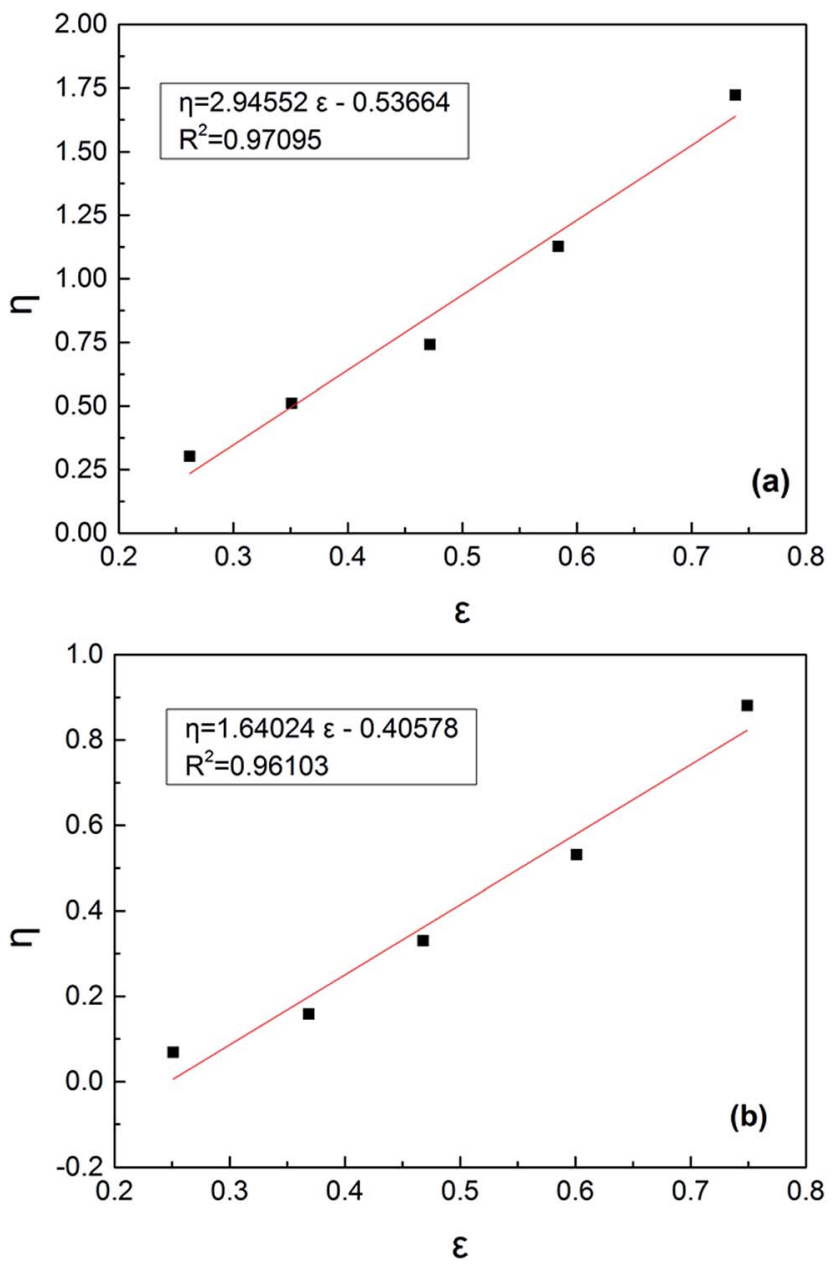

Fig. 2 Kelen-Tüdös figure of AM and DMC reactivity ratio under (a) T/ $\mathrm{D}=0$ and $(\mathrm{b}) \mathrm{T} / \mathrm{D}=1.0$.

Table 3 Results of reactivity ratios by Kelen-Tüdös method under T/ $\mathrm{D}=0$ and $\mathrm{T} / \mathrm{D}=1.0$

\begin{tabular}{lll}
\hline Conditions & $r_{\mathrm{AM}}$ & $r_{\mathrm{DMC}}$ \\
\hline $\mathrm{T} / \mathrm{D}=0$ & 2.4089 & 0.7012 \\
$\mathrm{~T} / \mathrm{D}=1.0$ & 1.5997 & 0.9508
\end{tabular}

distribution of the polymer sequence, in particular the distribution of cationic sequences, and facilitated the formation of the micro-blocks.

\subsection{Characterization}

3.3.1. FTIR spectra. Fig. 3 shows that the possible functional groups in PA-D 2 , TPA- $\mathrm{D}_{2}, \mathrm{PA}-\mathrm{D}_{5}$ and TPA-D $\mathrm{D}_{5}$ were characterized by FT-IR. The broad characteristic absorption peaks around $3436.53 \mathrm{~cm}^{-1}$ was assigned to the stretching vibration of $-\mathrm{NH}_{2}$ groups in the AM units. The adsorption peaks around 1133.94, 1661.86 and $2939.47 \mathrm{~cm}^{-1}$ were attributed to $-\mathrm{C}-\mathrm{O}-\mathrm{C}-,-\mathrm{C}=\mathrm{O}$ and $-\mathrm{CH}_{3}$ asymmetric stretching vibration respectively. ${ }^{22,32}$ The band in the vicinity of $954.59 \mathrm{~cm}^{-1}$ in spectra was assigned to the characteristic absorption of $\mathrm{N}^{+}\left(\mathrm{CH}_{3}\right)_{3} \cdot{ }^{25}$ What should not be overlooked was the intensity differences in the quaternary ammonium salt peak between

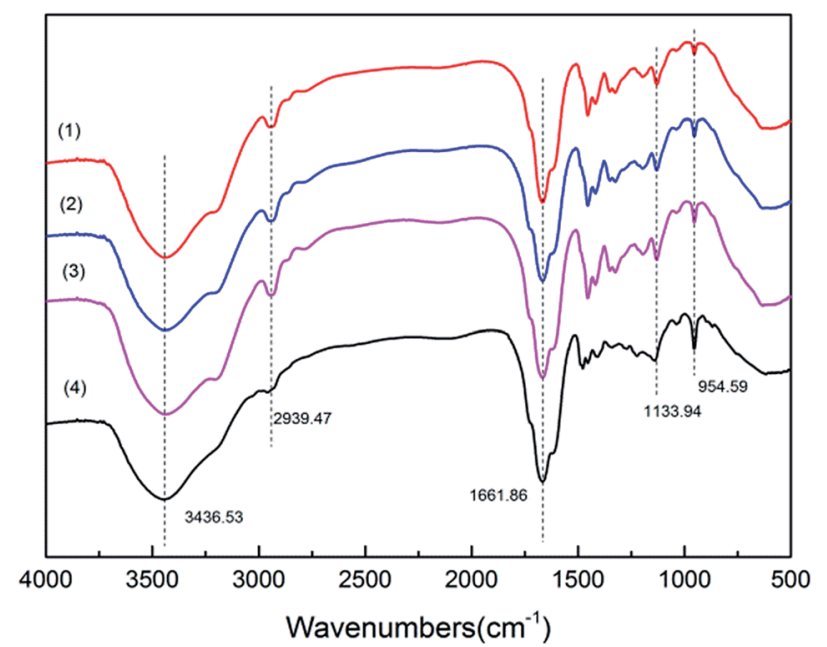

Fig. 3 Comparison of FITR spectra for (1) PA- $D_{2}$, (2) TPA- $D_{2}$, (3) PA-D and (4) TPA-D 5 .

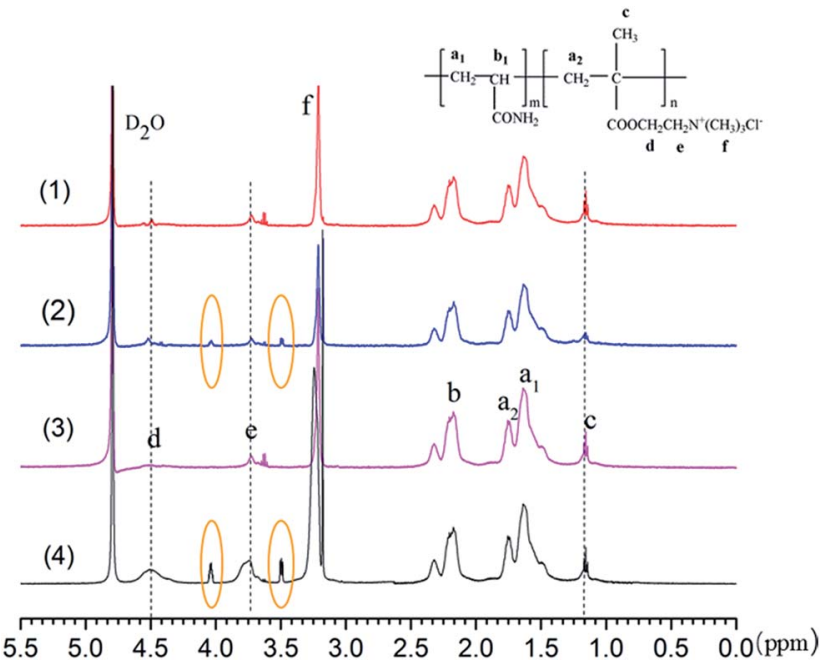

Fig. 4 Comparison of ${ }^{1} \mathrm{H}$ NMR spectra for (1) $P A-D_{2}$, (2) TPA- $D_{2}$, (3) PA-D 5 and (4) TPA-D . 

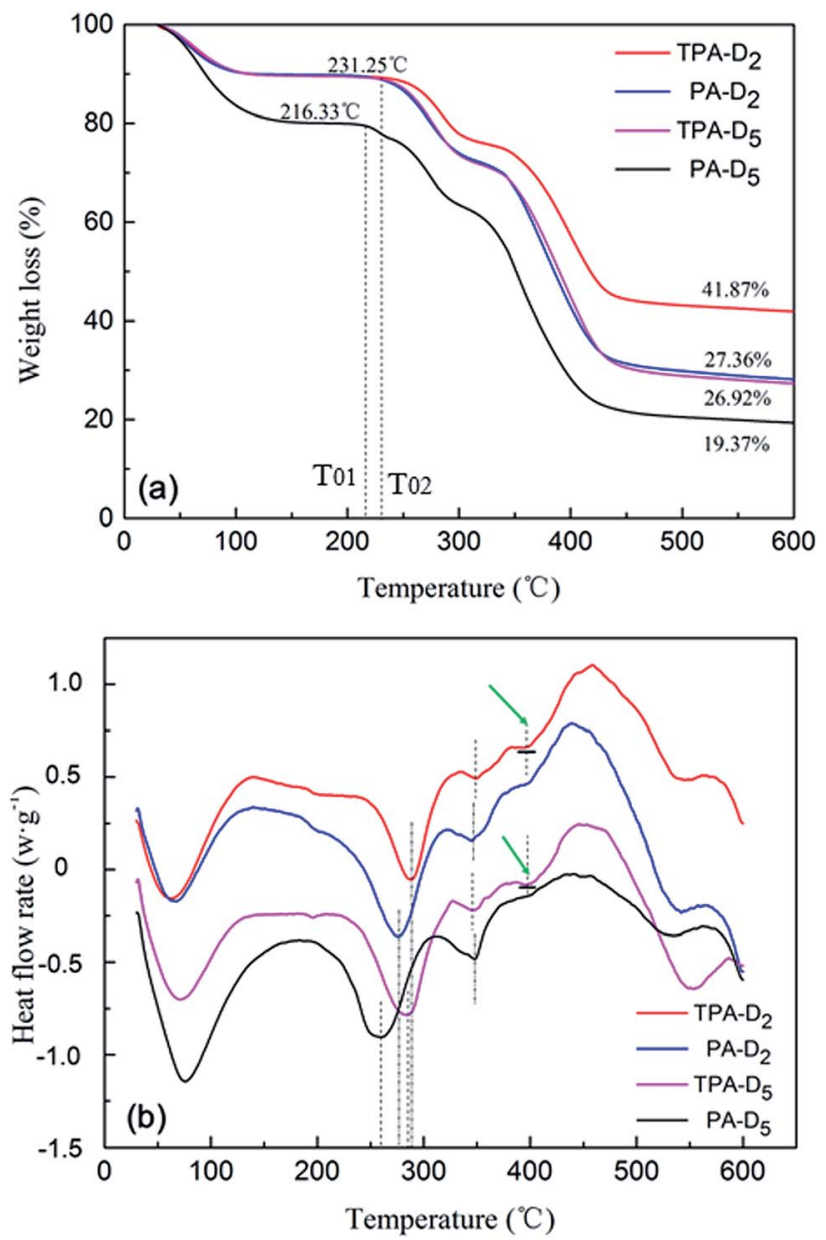

Fig. 5 Comparison of (a) TGA and (b) DSC for PA- $D_{2}, T P A-D_{2}, P A-D_{5}$ and TPA- $\mathrm{D}_{5}$. template-assembled polymers and random polymers under the same $f_{\mathrm{DMC}}$. The differences may be related to the increase of DMC monomers homo-polymerization in the presence of the template. In brief, the aforementioned characteristic peaks indicated that the product was a copolymer of AM and DMC monomers.

3.3.2. ${ }^{1} \mathbf{H}$ NMR spectra. The ${ }^{1} \mathrm{H}$ NMR spectra depicted in Fig. 4 further confirmed the effect of template on the formation of micro-blocks structure in the copolymer. The ${ }^{1} \mathrm{H}$ NMR curves exhibited similar vibration peaks, but the difference of proton characteristic peak intensities cannot be neglected. The asymmetric peaks at $\mathrm{H}_{\mathrm{a} 1}$ proton (1.628 $\mathrm{ppm}$ ) and $\mathrm{H}_{\mathrm{b}}$ proton (2.191 $\mathrm{ppm})$ were derived from the resonances of methylene $\left(-\mathrm{CH}_{2}-\right)$ and methine (- $\mathrm{CH}-)$ protons in AM monomers. ${ }^{33}$ Relatively, the asymmetric peaks of methylene $\left(-\mathrm{CH}_{2}-\right)$ groups in DMC monomers were shifted to $\mathrm{H}_{\mathrm{a} 2}$ proton (1.745 ppm). Besides, $\mathrm{H}_{\mathrm{c}}$ proton (1.159 ppm), $\mathrm{H}_{\mathrm{d}}$ proton (4.497 $\mathrm{ppm}$ ), $\mathrm{H}_{\mathrm{e}}$ proton (3.723 $\mathrm{ppm}), \mathrm{H}_{\mathrm{f}}$ proton (3.208 $\mathrm{ppm}$ ) were assigned to protons of $-\mathrm{CH}_{3}$, $-\mathrm{O}-\mathrm{CH}_{2}-,-\mathrm{CH}_{2}-\mathrm{N}^{+}-$, and $-\mathrm{N}^{+}-\left(\mathrm{CH}_{3}\right)_{3}$ in DMC monomers, respectively. ${ }^{11,25}$ Slightly different phenomenon can be observed that the proton characteristic signal intensity of $-\mathrm{N}^{+}-\left(\mathrm{CH}_{3}\right)_{3}$, $-\mathrm{CH}_{2}-\mathrm{N}^{+}$- and $-\mathrm{CH}_{3}$ in template-assembled polymers TPA- $\mathrm{D}_{2}$ and TPA-D $\mathrm{D}_{5}$ was stronger than random polymers PA- $_{2}$ and PA$\mathrm{D}_{5}$, correspondingly and respectively. The differences in peak intensities were closely related to the differences in polymer composition, such as $F_{\mathrm{DMC}}$, thereby leading to the difference in flocculation performance of the polymer. Notably, there are two new peaks surrounded by an elliptical circle in the ${ }^{1} \mathrm{H}$ NMR spectra of TPA- $\mathrm{D}_{2}$ and TPA- $\mathrm{D}_{5}$, which was believed to correlate with the stereo-complexes and micro-blocks of the copolymer, and was reflected in the subsequent sludge dewatering performance. ${ }^{18,20}$ According to this phenomenon, it can be concluded
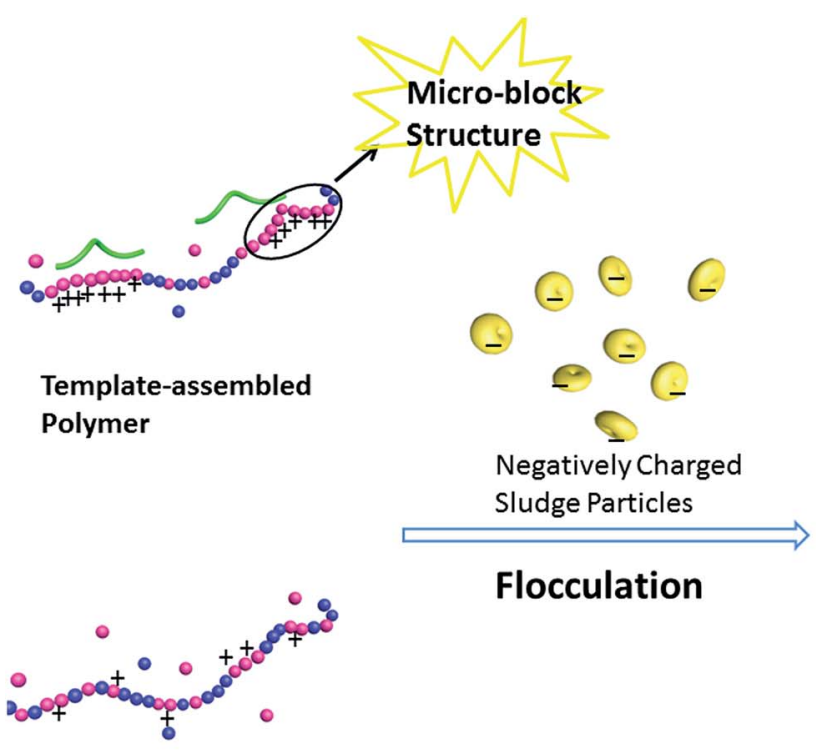

Random Polymer

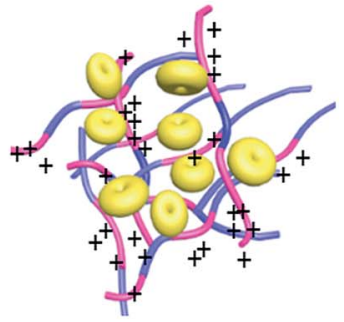

\section{Charge Attraction and Bridging}

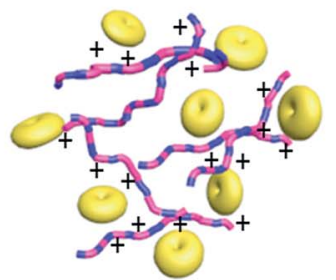

Fig. 6 Schematic of flocculation comparison for template-assembled polymer and random polymer. 
that several cationic micro-block structures did exist in the template-assembled polymer. Thence, the comparative analysis of ${ }^{1} \mathrm{H}$ NMR spectra further confirmed the formation of the micro-block structure in the template-assembled polymers.

3.3.3. DSC-DTA analysis. The thermal stability of the synthesized polymers was analyzed by TGA and DSC. As depicted in Fig. 5a, the four polymers showed three weight loss stages, but the weight loss rate was distinct at the parallel temperature. The first stage of decomposition occurs in the range of $30-231.25{ }^{\circ} \mathrm{C}$ for TPA- $_{2}$, PA- $\mathrm{D}_{2}$, TPA- $\mathrm{D}_{5}$, but $30-$ $216.33{ }^{\circ} \mathrm{C}$ for PA- $\mathrm{D}_{5}$, which can be attributed to the evaporation of intra and intermolecular moisture adsorbed by strong hydrophilic groups in the polymer. ${ }^{22}$ Therefore, the temperature $T_{0}$ should be regarded as the true starting point of polymer decomposition, and the decomposition point $T_{02}\left(216.33^{\circ} \mathrm{C}\right)$ for PA-D ${ }_{5}$ was lower than $T_{01}\left(231.25^{\circ} \mathrm{C}\right)$ for TPA-D ${ }_{2}$, PA-D $\mathrm{D}_{2}$, TPA-D ${ }_{5}$. Moreover, at any temperature in the decomposition stage after $T_{0}$, the weight loss rate of PA- $\mathrm{D}_{5}$ was the largest, TPA- $\mathrm{D}_{2}$ was the smallest, PA- $\mathrm{D}_{2}$ and TPA- $\mathrm{D}_{5}$ were similar and in the middle. This is because the thermal stability of DMC monomers was relatively poor to AM monomers, and the micro-blocks forced the polymer to be more thermally stable. ${ }^{22,34}$ Similarly, as it can be seen from the DSC analysis (Fig. 5b), the greater the weight loss rate, the more the endothermic amount of polymer; in addition, a weak absorption peak appeared at about $400{ }^{\circ} \mathrm{C}$ in the third weight-loss stage of the template-assembled polymer TPA- $\mathrm{D}_{2}$ and TPA- $\mathrm{D}_{5}$, which may be related to the existence of micro-blocks, and reflected in the subsequent sludge dewatering performance.

\subsection{Dewatering performance}

Some external factors can greatly affect the flocculation performance of flocculants, in particular, the dosage and the $\mathrm{pH}$ of the application system. ${ }^{35}$ Herein, the sludge dewatering experiments mainly focused on investigating the influence of the dosage and $\mathrm{pH}$, and taking the SRF and $\xi$-potential as the main index. The random polymer $\mathrm{PA}-\mathrm{D}_{2}$ (with same feed ratio $f_{\mathrm{DMC}}$ as TPA- $\mathrm{D}_{2}$ ) and PA- $\mathrm{D}_{3}$ (similar monomer composition ratio $F_{\text {DMC }}$ ) were selected for application in sludge dewatering. The intrinsic viscosity $[\eta]$ and CD of flocculants TPA- $\mathrm{D}_{2}$, PA- $\mathrm{D}_{3}$ and PA-D ${ }_{2}$ were $10.31 \mathrm{dL} \mathrm{g}^{-1}, 18.07 \% ; 10.83 \mathrm{dL} \mathrm{g}^{-1}, 17.65 \%$ and $10.35 \mathrm{dL} \mathrm{g}^{-1}, 10.28 \%$, respectively, as shown in Table 2 . Schematic of flocculation process comparison for templateassembled polymer and random polymer was shown in Fig. 6 .

3.4.1. Dosage dependence. The dosage-dependence on sludge dewatering performance of the template-assembled polymer TPA- $\mathrm{D}_{2}$ and the random polymers $P A-\mathrm{D}_{3}$ and PA- $\mathrm{D}_{2}$ was depicted in Fig. 7. According to the value of SRF, sludge dehydration performance can be divided into three grades: bad dewaterability $\left(>10 \times 10^{12} \mathrm{~m} \mathrm{~kg}^{-1}\right)$, medium dewaterability (5-9 $\left.\times 10^{12} \mathrm{~m} \mathrm{~kg}^{-1}\right)$ and good dewaterability $\left(<4 \times 10^{12} \mathrm{~m} \mathrm{~kg}^{-1}\right) \cdot{ }^{36}$ Fig. 7a shows that, when the dosage $\geq 40 \mathrm{mg} \mathrm{L}^{-1}$, the SRF of sludge treated with TPA- $\mathrm{D}_{2}$ and PA- $\mathrm{D}_{3}$ obtained good dewaterability for the intrinsic viscosity and $\mathrm{CD}$ were quite close and relatively ideal. The optimum dosage and the optimal sludge SRF of TPA-D ${ }_{2}$ was nearby $40 \mathrm{mg} \mathrm{L}^{-1}$ and $1.69 \times 10^{12} \mathrm{~m} \mathrm{~kg}^{-1}$ respectively, while that for PA- $\mathrm{D}_{3}$ was $50 \mathrm{mg} \mathrm{L}^{-1}$ and $2.06 \times 10^{12}$ $\mathrm{m} \mathrm{kg}^{-1}$, displayed slightly difference. In contrast, sludge dewatering performance for PA- $\mathrm{D}_{2}$ was worse than that for TPA- $\mathrm{D}_{2}$ and PA- $\mathrm{D}_{3}$, the optimum sludge SRF only achieved $3.36 \times 10^{12}$ $\mathrm{m} \mathrm{kg}^{-1}$ with the dosage of $50 \mathrm{mg} \mathrm{L}^{-1}$. It was obvious that due to the higher $\mathrm{CD}$ value at similar intrinsic viscosities, TPA- $\mathrm{D}_{2}$ and PA- $\mathrm{D}_{3}$ exhibited much better flocculation efficiency than PA- $\mathrm{D}_{2}$. Notably, template-assembled polymer TPA- $\mathrm{D}_{2}$ showed slightly better flocculation performance than random polymer $\mathrm{PA}-\mathrm{D}_{3}$ at same intrinsic viscosities and $\mathrm{CD}$ value, for the presence of cationic hydrophobic micro-blocks strengthened the charge neutralization and hydrophobicity of TPA- $\mathrm{D}_{2}{ }^{26}$ Overall, the three flocculants decreased rapidly with the increase of the dosage and then slightly increased. When the dosage exceeds the optimal dosage to a certain range, the opposite situation occurs, that is, the deterioration trend on sludge dewatering effect for polymer TPA- $\mathrm{D}_{2}$ was more obvious, which can be attributed to the stronger electrostatic repulsion caused by the re-take positively charged sludge. ${ }^{30}$ The curve shown in Fig. $7 \mathrm{~b}$ reveals that the sludge system with TPA- $\mathrm{D}_{2}$ added showed higher $\zeta$-potential and achieved the isoelectric point at smaller
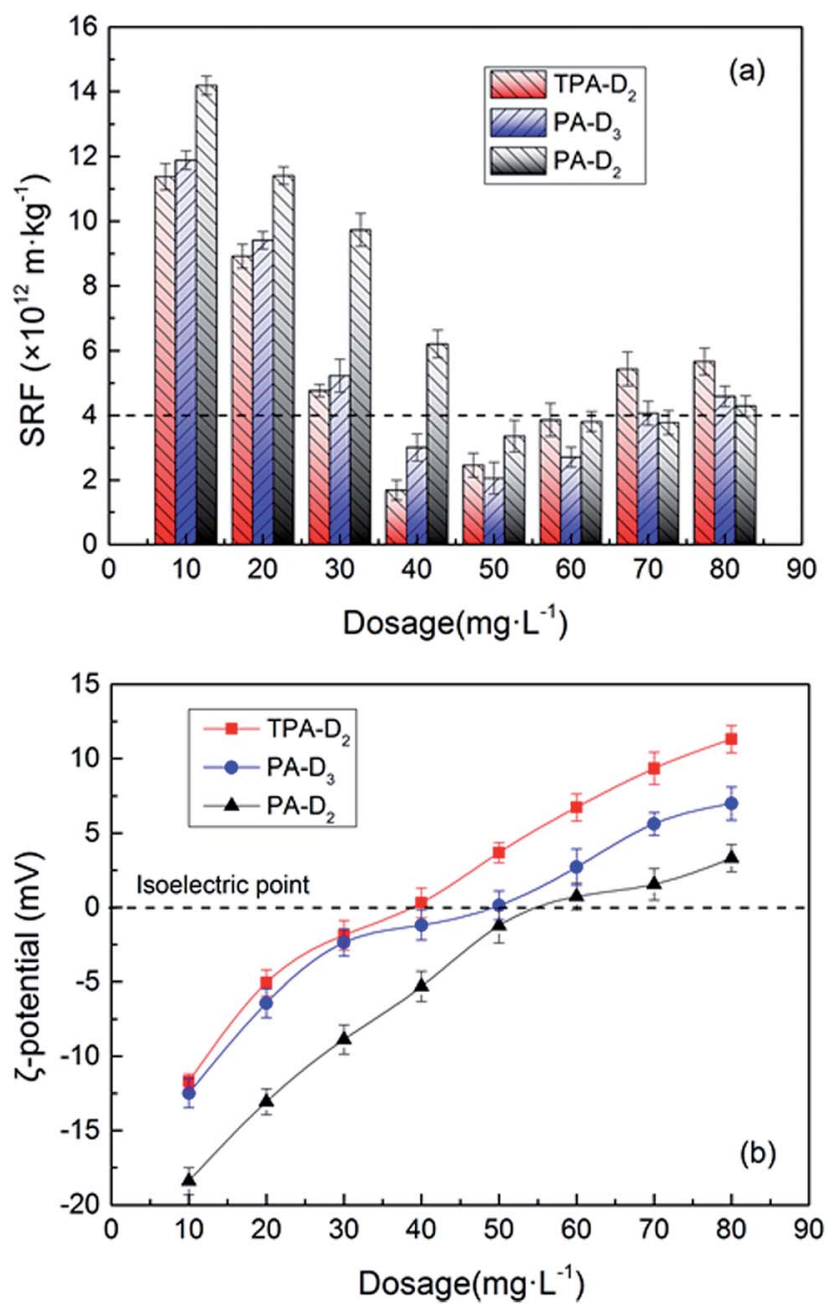

Fig. 7 Dosage dependence of TPA-D,$P A-D_{3}$ and PA-D on the (a) SRF and (b) $\zeta$-potential. 
dosage of $40 \mathrm{mg} \cdot \mathrm{L}^{-1}$, which indicated that TPA- $\mathrm{D}_{2}$ has stronger charge neutralization than $\mathrm{PA}-\mathrm{D}_{3}$ and $\mathrm{PA}-\mathrm{D}_{2}$. It was well known that the destabilized colloids system exhibited stronger charge neutralization at the isoelectric point. ${ }^{33}$ Taken together, the results suggested that both the presence of cationic hydrophobic micro-blocks at same intrinsic viscosities and CD, and the higher $\mathrm{CD}$ value at same feed ratio $f_{\mathrm{DMC}}$ enhanced the charge neutralization and hydrophobicity ability of templateassembled polymer.

3.4.2. $\mathrm{pH}$ dependence. The $\mathrm{pH}$ of the system could exert a great influence on the flocculation performance of the polymers and caused the $\zeta$-potential to change greatly. Some researches have shown that the effect of $\mathrm{pH}$ on the sludge dewatering may be related to the breakage of polymeric matrix extracellular polymeric substances, which accounts for nearly $60-80 \%$ of total sludge mass and significantly affect the surface chargeability, floc stability and rheological behavior of sludge..$^{6,37,38}$ Herein, the dosage of three flocculants was fixed as $50 \mathrm{mg} \mathrm{L}{ }^{-1}$. As shown in Fig. 8a, it was obvious that the SRF of the treated sludge decreased drastically at the point of $\mathrm{pH}=2$. It was confirmed that the extracellular polymeric substances was decomposed when the acidity was close to 2 , and released
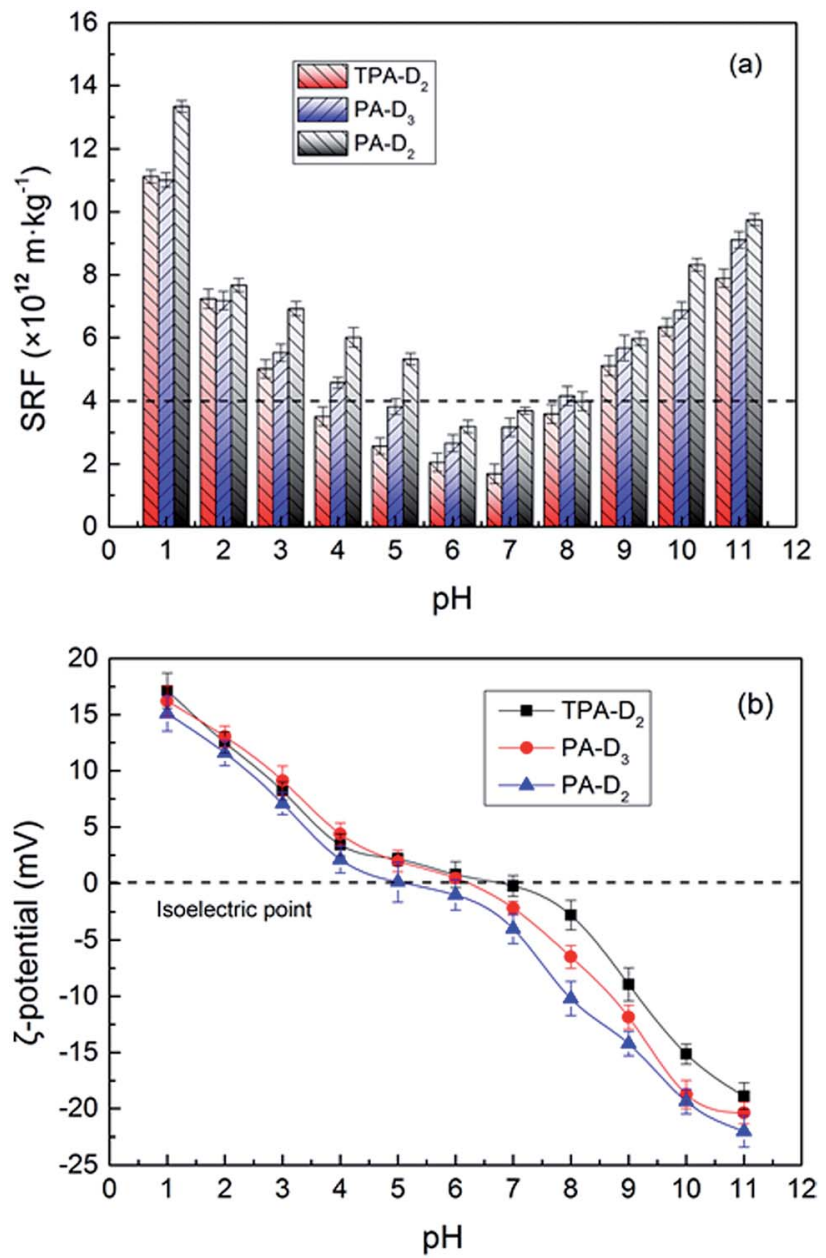

Fig. $8 \mathrm{pH}$ dependence of TPA- $D_{2}, P A-D_{3}$ and $P A-D_{2}$ on the (a) SFR and (b) $\zeta$-potential. a large amount of bound water that difficult to remove. ${ }^{39}$ Overall, the SRF of sludge decreased sharply with the increase of $\mathrm{pH}$, then rapidly increased, and be the lowest in the neutral and weakly acidic conditions. This phenomenon was related to the changes in the ionization degree of the ionic group in
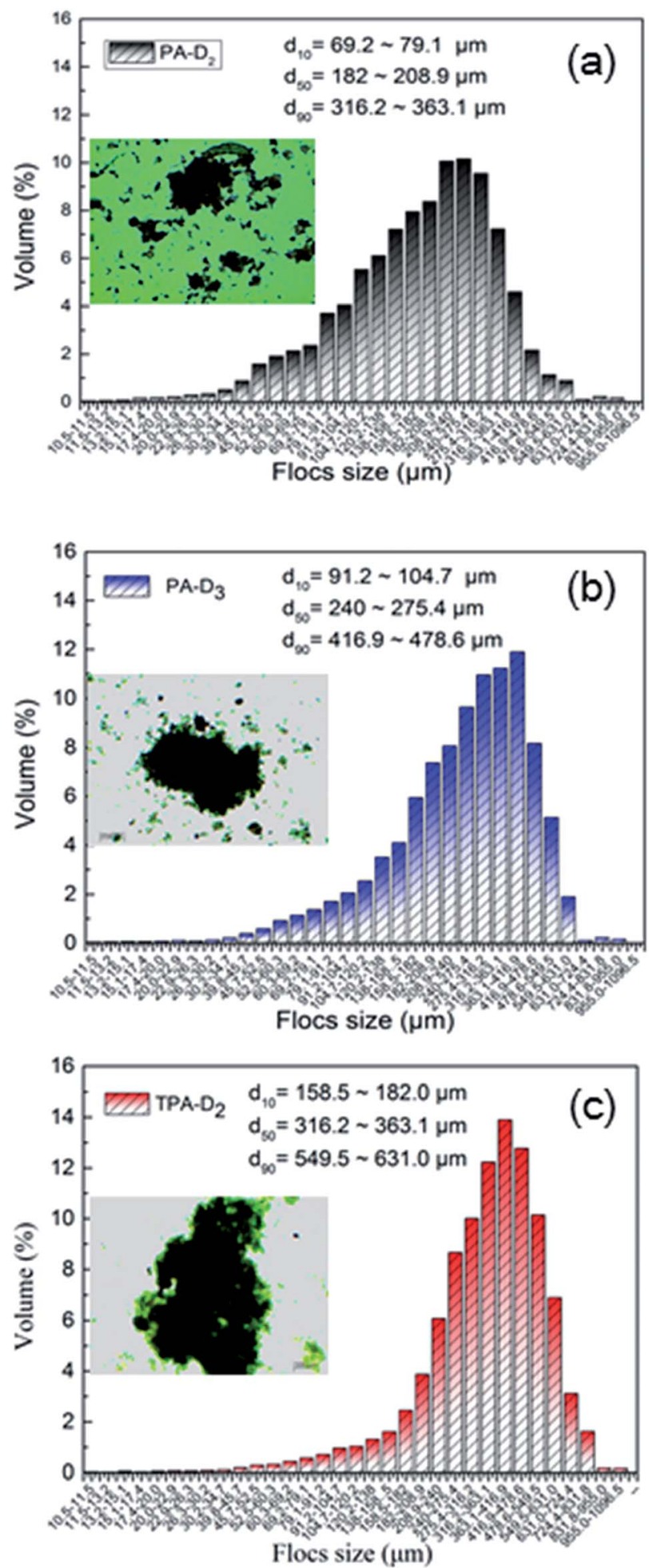

Fig. 9 Size distribution and morphology of sludge flocs treated with (a) $P A-D_{2}$, (b) $P A-D_{3}$ and (c) $T P A-D_{2}$. 
quaternary ammonium salt ${ }^{\mathbf{1 1}}$ and the sludge flocs surface properties. The $\mathrm{pH}$ range of relatively optimal flocculation effects for template-assembled polymer TPA-D $_{2}$ was 4-8, whereas that for the random polymer $\mathrm{PA}-\mathrm{D}_{3}$ and $\mathrm{PA}-\mathrm{D}_{2}$ was $5-7$ and 6-7, respectively. Correspondingly, as shown in Fig. 8b, the $\zeta$-potential of TPA-D $\mathrm{D}_{2}$ under weak acid weak base and neutral conditions was closer to the isoelectric point, while the random polymer $\mathrm{PA}-\mathrm{D}_{3}$ and $\mathrm{PA}-\mathrm{D}_{2}$ achieved that only under weak acid and neutral conditions. Thence, it can be concluded that the formation of micro-blocks structure allows the polymer to have better $\mathrm{pH}$ adaptability.

3.4.3. Flocs performance and sedimentation. To examine the effect of micro-blocks and charge density CD on flocculation performance, the flocs characteristics including floc size distribution, morphology and sedimentation behavior of the sludge treated with different flocculants were comparative investigated. Fix dosage as $50 \mathrm{mg} \mathrm{L}^{-1}$ and the $\mathrm{pH}$ as the natural pH of raw sludge. Fig. 9 shows that the size value $d_{10}, d_{50}$ and $d_{90}$ of the flocs treated with TPA-D $\mathrm{D}_{2}$ were larger than that with PA-D and $P A-D_{2}$, and the size distribution narrower and more concentrated. As shown in Fig. S2, $\uparrow$ TPA-D $\mathrm{D}_{2}$-treated sludge flocs were tightly connected and stacked, large and densely granulated and with many large voids on the surface of the flocs. Whereas $\mathrm{PA}-\mathrm{D}_{3}$-treated sludge flocs were relatively loose, and the supernatant was turbid. In contrast, $P A-\mathrm{D}_{2}$-treated sludge flocs exhibited coarse-grained morphology, and granulated loosely and uniformly. The sludge flocs were further observed and compared by optical microscope images, and the results were shown as the embedded graph in Fig. 9 and $\mathrm{S} 2, \uparrow$ respectively. The sedimentation behavior of sludge was closely related to sludge-water separation performance, which was depend upon the structure of sludge flocs including particle size, floc density, and forth on. ${ }^{30}$ The sedimentation behavior of the sludge flocs with time was plotted in Fig. 10. Herein, the rate of sludge-water interfacial height variation over time in $10 \mathrm{~min}$ was assumed to be the sludge sedimentation rate. It can be estimated that the sedimentation rate of TPA- $\mathrm{D}_{2}$-treated sludge was $1.509 \mathrm{~min}^{-1}$, while that of $P A-D_{3}$-treated sludge and $P A-D_{2}$ treated sludge was $1.357 \mathrm{~cm} \min ^{-1}$ and $1.063 \mathrm{~cm} \mathrm{~min} \min ^{-1}$,

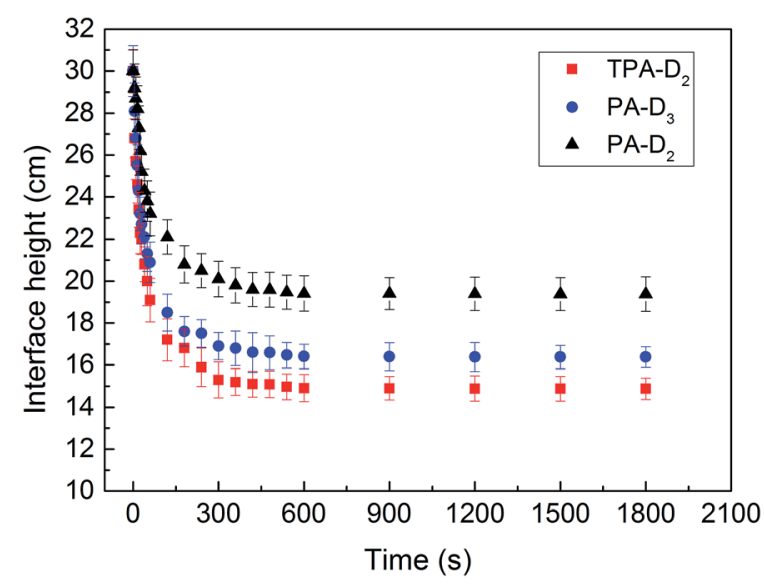

Fig. 10 Comparison of sedimentation behavior of sludge flocs. respectively. Based on the findings discussed above, it can be concluded that the combined effect of the compact structure and large size of the sludge floc effectively improved the sedimentation property.

\section{Conclusions}

An amphiphilic electrolyte P(AM-DMC) with cationic hydrophobic micro-blocks structure was synthesized by template assembly method. The micro-blocks were generated by the new distribution of sequence in the presence of template, and closely related to the changes of the reactivity ratio $\left(r_{\mathrm{AM}}\right.$ and $r_{\text {DMC }}$ ). The micro-blocks were confirmed by ${ }^{1} \mathrm{H}$ NMR and DSCTGA analysis. Compared with random polymer $\mathrm{PA}-\mathrm{D}_{3}$ and $\mathrm{PA}-$ $\mathrm{D}_{2}$, template-assembled polymer $T P A-\mathrm{D}_{2}$ showed a relative superiority in the sludge dewatering due to its lower optimum dosage, wider $\mathrm{pH}$ adaptation range, and TPA- $\mathrm{D}_{2}$-treated sludge flocs were more compact, larger and settling faster. The optimum SRF values of sludge treated with $T P A-D_{2}$ reached nearly $1.69 \times 10^{12} \mathrm{~m} \cdot \mathrm{kg}^{-1}$ under the conditions of a lower dosage $40 \mathrm{mg} \mathrm{L}^{-1}$, and the $\mathrm{pH}$ application range was 4-8. All the results indicated that the existence of template did play a role of molecular assembly in the radical polymerization, and the cationic hydrophobic micro-blocks in the polymer slightly improved the sludge dehydration performance.

\section{Acknowledgements}

The authors gratefully acknowledge the financial support of the National Natural Science Foundation of China (Project No. 21677020 and No. 21477010).

\section{References}

1 Z. Zhang, S. Xia and J. Zhang, Water Res., 2010, 44, 30873092.

2 Y. Qi, K. B. Thapa and A. F. A. Hoadley, Chem. Eng. J., 2011, 171, 373-384.

3 Q. Lin, H. Peng, S. Zhong and J. Xiang, J. Hazard. Mater., 2015, 285, 199-206.

4 X. Z. Meng, A. K. Venkatesan, Y. L. Ni, J. C. Steele, L. L. Wu, A. Bignert, A. Bergman and R. U. Halden, Environ. Sci. Technol., 2016, 50, 5454-5466.

5 G. H. Yu, P. J. He, L. M. Shao and P. P. He, Environ. Sci. Technol., 2008, 42, 7944-7949.

6 Z. Chen, W. Zhang, D. Wang, T. Ma, R. Bai and D. Yu, Water Res., 2016, 103, 170-181.

7 M. S. Kim, K. M. Lee, H. E. Kim, H. J. Lee, C. Lee and C. Lee, Environ. Sci. Technol., 2016, 50, 7106-7115.

8 K. Xiao, Y. Chen, X. Jiang, V. K. Tyagi and Y. Zhou, Water Res., 2016, 105, 470-478.

9 S. Bratskaya, S. Schwarz and D. Chervonetsky, Water Res., 2004, 38, 2955-2961.

10 G. V. Franks, J. Colloid Interface Sci., 2005, 292, 598-603.

11 D. Chen, X. Liu, Y. Yue, W. Zhang and P. Wang, Eur. Polym. J., 2006, 42, 1284-1297. 
12 W. L. Yan, Y. L. Wang and Y. J. Chen, Water Res., 2013, 47, 6445-6456.

13 R. Hogg, J. Colloid Interface Sci., 1984, 102, 232-236.

14 D. K. S. L. Besra, S. K. Roy and P. Ay, Int. J. Miner. Process., 2002, 66, 183-202.

15 Z. Yang, J. R. Degorce-Dumas, H. Yang, E. Guibal, A. Li and R. Cheng, Environ. Sci. Technol., 2014, 48, 6867-6873.

16 J. Kleimann, C. Gehin-Delva, H. Auweter and M. Borkovec, Langmuir, 2005, 21, 3688-3698.

17 Y. Zhou and G. V. Franks, Langmuir, 2006, 22, 6775-6786.

18 H. L. Frisch and Q. H. Xu, Macromolecules, 1992, 25, 51455149.

19 I. Rainaldi, C. Cristallini, G. Ciardelli and P. Giusti, Macromol. Chem. Phys., 2000, 201, 2424-2431.

20 S. Polowiński, Prog. Polym. Sci., 2002, 27, 537-577.

21 Y. X. Zhang, F. P. Wu, M. Z. Li and E. J. Wang, J. Phys. Chem. $B, 2005,109,22250-22255$.

22 Q. Q. Guan, H. L. Zheng, J. Zhai, C. Zhao, X. Zheng, X. Tang, W. Chen and Y. J. Sun, Ind. Eng. Chem. Res., 2014, 53, 5624-5635.

23 D. Cuccato, G. Storti and M. Morbidelli, Macromolecules, 2015, 48, 5076-5087.

24 H. Ren, W. Chen, Y. Zheng and Z. Luan, React. Funct. Polym., 2007, 67, 601-608.

25 Z. Abdollahi, M. Frounchi and S. Dadbin, J. Ind. Eng. Chem., 2011, 17, 580-586.

26 T. Lü, X. Liu, D. Qi and H. Zhao, Iran. Polym. J., 2015, 24, 219227.
27 J. J. Shen, L. L. Ren and Y. Y. Zhuang, J. Hazard. Mater., 2006, 136, 809-815.

28 D. Arunbabu, Z. Sanga, K. M. Seenimeera and T. Jana, Polym. Int., 2009, 58, 88-96.

29 J. P. Wang, Y. Z. Chen, Y. Wang, S. J. Yuan, G. P. Sheng and H. Q. Yu, RSC Adv., 2012, 2, 494-500.

30 W. Chen, H. L. Zheng, Q. Q. Guan, H. Teng, C. L. Zhao and C. Zhao, Ind. Eng. Chem. Res., 2016, 55, 2892-2902.

31 J. P. Wang, S. J. Yuan, Y. Wang and H. Q. Yu, Water Res., 2013, 47, 2643-2648.

32 Y. Liao, H. L. Zheng, L. Qian, Y. J. Sun, L. Dai and W. W. Xue, Ind. Eng. Chem. Res., 2014, 53, 11193-11203.

33 H. L. Zheng, J. Y. Ma, C. Zhu, Z. Zhang, L. Liu, Y. Sun and X. Tang, Sep. Purif. Technol., 2014, 123, 35-44.

34 J. A. Mapkar, G. Iyer and M. R. Coleman, Appl. Surf. Sci., 2009, 255, 4806-4813.

35 R. Rojas-Reyna, S. Schwarz, G. Heinrich, G. Petzold, S. Schütze and J. Bohrisch, Carbohydr. Polym., 2010, 81, 317-322.

36 Z. Chen, W. J. Zhang, D. S. Wang, T. Ma and R. Y. Bai, Water Res., 2015, 83, 367-376.

37 M. Raynaud, J. Vaxelaire, J. Olivier, E. Dieude-Fauvel and J. C. Baudez, Water Res., 2012, 46, 4448-4456.

38 P. Zhang, Y. P. Chen, J. S. Guo, Y. Shen, J. X. Yang, F. Fang, C. Li, X. Gao and G. X. Wang, Water Res., 2014, 57, 31-39.

39 Y. G. Chen, H. Z. Yang and G. W. Gu, Water Res., 2001, 35, 2615-2620. 